\title{
Testing a Model of Business Leader's Inclination toward a Promising Prospective Endeavor - A Study
}

\author{
Dr. G. P. Mishra, \\ Professor, \\ Department of Management, \\ Birla Institute of Technology Mesra \\ Ranchi Extension Centre, \\ Jaipur, Rajasthan, India.
}

\author{
Kusum Lata Mishra, \\ Associate Lecturer, \\ Department of Management, \\ Birla Institute of Technology Mesra \\ Ranchi Extension Centre, \\ Jaipur, Rajasthan, India.
}

(Received December 23, 2019; Accepted January 25, 2020)

\begin{abstract}
In today's world, people explore new option of recreating themselves apart from getting relieve from the stressful environment, therefore this paper attempts to analyze inclination toward a promising prospective endeavor and tries to understand the customers preferences toward the new concept of recreation through this business venture. This paper explores the entrepreneurial opportunities of starting a new venture by business leaders on pure and fragrant oxygen for the potential customers. The findings of research is based on 200 samples comprising of local population and tourists in the age group of 20-40 years. The result based on pilot study and feasibility analysis provide insight about the feasibility of starting a venture in Oxygen Bar suggesting its futuristic venture in the Middle East region.
\end{abstract}

Keywords: Business Leaders, venture, entrepreneurship.

\section{INTRODUCTION:}

The first official oxygen bar was introduced in Toronto, Canada, in 1996, but it later got more customer attraction toward this type of business (DePalma, 1997). According to (Breathe O2 2011), "the first Oxygen Bar in the United States was the "O2 Zone" opened by Mark Zarubi and Ted Mitchell in Reno Nevada in 1996. Zarubi and Mitchell contracted with Kevin McFarland of Tekland Engineering to design and produce the first Oxygen bar equipment" (Breathe O2, 2011). According to (Daller 2017) "since oxygen bars were introduced in the United States in the late 1990s, the trend has caught on, and customers are bellying up to bars around the country to sniff oxygen through a plastic hose (Cannula) inserted into their nostrils. Many patrons opt for the "flavored" oxygen produced by pumping oxygen through an aroma en route to the nose". By late 90's, the $\mathrm{O} 2$ spa bars had become quite common in most of the regions namely New York, Florida, Las Vegas and in many other parts of North America and other western countries. Now these types of oxygen bars can be even found in café's, restaurants, smoke bars, health clubs and casinos etc. even at private parties, they prefer to give this for their guests. It has now flown to the GCC nations also. According to (Gulf News General 2017) "The craze has caught on and they're cropping up everywhere. Dubai has opened its first one called O2 World located in The Atrium Centre in Bur Dubai." In earlier times also here was a trend of gaining attraction of the western cultures. It has now started in UAE, Kuwait, Qatar and other GCC countries. They have welcomed this concept with both their hands. At this bar, patrons can improve their health and vitalize their energy. The customer can come here and sit comfortably in the wide leather seats and put a tube in their nose, which is connected to the oxygen machine. It is a 15-minute-long session, were they can open and close or switch between the four essences. 15 minutes for each session was set as it's enough to get the benefits of oxygen, but the client can take another session if they wish to do so. 


\section{Small Business Scenario in Oman:}

According to Public Authority for small and medium enterprises development, Oman (RIYADA, 2018), micro enterprises is defined as enterprise employing less than 5 employees with annual sales less than 100,000 Omani Rial whereas small enterprises is defined as enterprise employing between 6 to 20 employees with annual sales between 100,000 to 500,000 Omani Rial, medium enterprises is defined as enterprise employing between twenty 6-90 employees with annual sales between 500,000 to 3 million Omani Rial. According to (World Bank report 2010), the developed countries produce new ventures more than 10 times as compared to the Middle East nations. This shows that Middle East nations lag far behind in producing new business as compared to the developed economies of the world. Moreover (Reynolds et al. 2004) state that in Middle East nations, entrepreneurship activity is "necessity entrepreneurship" and not opportunity driven (Porter, 2003) state that "Oman's economy is suffering from an underlying entrepreneurial malaise, which without action, will hinder economic growth"; therefore the concept of entrepreneurship is the only important area where government should focus. For instance, in 2003, fewer than 2 in 100 were starting a new business, as compared to 1 in 10 in the US (MOM, 2005). According to (MOM, 2005) report in the last ten years there has not been a single IPO issued for a new high-growth venture in the Muscat Securities Market (MSM). As per (SME Oman report 2016), there is a lot of challenge faced by the entrepreneurs in Oman. One such challenge is scalability i.e. a lack of knowhow, business maturity and capacity building and second is lack of business opportunities as a result of a lack of trust between large companies and SME'S about the quality of deliverables and timely delivery. The economy of The Sultanate of Oman situated on the south eastern coast of the Arabian Peninsula is mainly dependant (84\%) on oil exports though it has diversified its economy relatively in the area of tourism (Central Intelligence Agency report, 2016). The report also states that tourism is the fastest-growing industry in Oman. Other sources of income, agriculture and industry, are small in comparison and account for less than $1 \%$ of the country's exports, but diversification is seen as a priority by the government. Hence Oman should try to capitalize on its capital, skill and knowledge as the opportunities for entrepreneurship exist normally on three key issues, they are- knowledge, skill and capital (UNDP, 2004). Therefore the background information of the project is as follows.

\section{SIGNIFICANCE OF THE STUDY:}

According to Desertcart (2017) "pure oxygen is the perfect way to energize and a few deep breaths of Boost Oxygen helps you stay at your best" and according to (Koninklijke 2017) "there are numerous advantages of using oxygen therapy, it can drastically improve your overall health by improving the health of your blood with a good amount of oxygen supply". The significance of this project is to let people know, what other alternatives can be taken to relax instead of Shisha. In Oman people are found of smoking shisha to relieve from stress which is also deadly. According to (GYTS-Oman 2010) report, 7.7\% of students were current shisha smokers, $9.9 \%$ of students were current cigarettes smokers and $3.9 \%$ were smokeless users. Shisha smoking is unhealthy, harmful, and also causes weakness in body. In a report published in (Times of Oman 2016), shisha smoking is causing lung cancer which is on the rise in Oman. According a report by World Health Organization (WHO, 2003), a Shisha smoker inhales as much smoke during one session as a cigarette smoker would inhale 100 or more cigarettes. According to (Gulf News Oman 2017), Oman's Shura Council voted to ban e- cigarettes and e-shisha in the year 2014 after medical studies found they contained cancer-causing substances. Therefore this study highlighted the harmful effects of Shisha and explored an healthy alternative of using "oxygen bar" which its proponents claim that purified oxygen produced a blitz of health benefits, including: reduced stress, increased energy, and increased alertness, Alleviation of symptoms of hangovers, headaches and sinus problems. On other hand, some people are suffering from long term effect, that's oxygen bar may help them to sleep better, wake up with more drive. The oxygen bar experience creates clarity of mind, feeling enhanced perception of high level of energy and relax. The American Lung Association cited in (Oxygenbars.com 2017) as mentioned that "breathing oxygen from an oxygen bar for less than 30 minutes (one oxygen bar session) has no harmful effects and there is no evidence that oxygen used in bars can be dangerous to a normal person's health". According to (Construction World 2016), Kuwait recently launched Oasis, the country's first oxygen bar. Located in Salmiya, near the Sultan Center, the bar houses 10 seats. It energizes the clients, uplifts and relieves them of headaches and other common results of stress manifestation. 


\section{Oxygen bar- A New Preference for Business Leaders:}

An oxygen bar is an enterprise or a business establishment that sells oxygen for recreational use and business leaders (Business leaders are those visionaries who constantly eye upon new business ventures) in the United States have tried to explore its potential in their market (Drahl, 2017). Oxygen is important for life, and a lack of oxygen can have negative effects on the human body including headaches, dizziness and loss of concentration. Ninety percent of the energy comes from oxygen, and only 10 percent from food and water. Individual flavored scents may be added to enhance the experience. The flavors in an oxygen bar appear from bubbles oxygen through bottles absolute ambrosial solutions before it alcove the nostrils: a lot of bars use food-grade particles to aftermath the scent, but some bars use aroma oils. According to (Susan 2017), many professionals like movie stars and football players use oxygen for recreation purpose that helps them to recover from the body exertions and stress. Susan (2017) mentions that oxygen bar is used by the athlete professional also because the oxygen boosts energy and provides them more stamina. Susan (2017) further states that oxygen bars have been used by the mountaineers and even used by the aging population worldwide. Susan (2017) mentions that "in the year 2017, the sales of consumer recreational oxygen equipment markets is estimated to be $\$ 44.5$ million, and they are anticipated to hit $\$ 2.1$ billion dollars by 2023. Professional athletes drive the market initially. Growth is a result of demand for the smaller lighter technology that's already been developed and is on the market, available for use by people exercising". According to (Globenewswire 2017) oxygen bars are also used by many singers to improve the quality of vocal cord and it is also used by film stars to improve the skin tone and therefore the market of oxygen bars is likely to grow substantially. According to Airheads Inc (2016) "An Airheads oxygen bar is a free-standing bar which people sit or stand at to breathe over $90 \%$ pure oxygen and aromatherapy from a disposable nasal Cannula (nose hose). These modular bars can service anywhere from one to eighteen people simultaneously and they are usually manned by one or two oxy-bartender/technicians". According to (WebMD 2017) Oxygen therapy boosts energy levels, increases the endurance during exercise, helps you bounce back more quickly from physical exertion, provides relief from stress and pollution, increases the concentration, helps you relax, and eases headaches and hangovers. According to (Altman 2007), Customers in these bars breathe oxygen through a plastic hose inserted into their nostrils. According to (Bren 2002) the oxygen from oxygen bar is produced from the ambient air by an industrial (non- medical) oxygen concentrator and inhaled through a nasal Cannula for up to about 20 minute. Bren (2002) further states that some oxygen bar companies offer safe water-based aromas for flavoring in order to maintain compliance and stay within FDA guidelines. Medicinenet (2017) states that since oxygen bars were introduced in the United States in the late 1990s, the trend has caught on and customers are bellying up to bars around the country to sniff oxygen through a plastic hose (Cannula) inserted into their nostrils Since this study was conducted in Shatti Al-Qurum area of Muscat in Oman, therefore we hypothesize that opening venture in "Oxygen Bars" would be successful given its background of fast growing sector in the area of tourism in the region. This paper explores the entrepreneurial opportunities of pure and fragrant oxygen to the potential customers. During this period, we visited similar projects to acquire information, to know about the procedures and the raw materials required for this type of business. This idea may be considered by many people in the Muscat and may also act as substitute to "Shisha smokers" which is harmful to health and found in these countries. Sisha is a type of smoking in which the smoke passes through the water-pipe body, bubbles through the water in the bowl, and is carried through the hose to the smoker (Shihadeh, 2003). Therefore as an innovative idea, we try to explore the opportunities. So, we hypothesize that-

\section{$H_{0^{-}}$Oxygen Bar can be used as a new entrepreneurial venture by the business leaders.}

\section{Entrepreneurial Tourism:}

According to (Khan and Krishnamurthy 2016), 33.2 percent of the respondents have shown interest to venture into this entrepreneurial tourism, i.e., to start their own tourism business in the area of Oxygen Bar. According to a study on the future of investment and growth by National Center for Statistics and Information (NSCI, 2017), that focused on the fiscal years 1998-2015, Oman is likely to pour future investments into tourism and digital communications. The study showed that there was a rise in tourism sector of 17.7 percent in the year 2015 with 2.6 million tourists spending over OMR 288.2 million while analysis of the previous year's showed a distinct upward trend from yearly average of 1.25 million per year between 1998-2008 to 1.99 million between 2009-2015. According to a report by National Center for 
Statistics and Information (NSCI, 2016) Oman, tourism sector contributed to 2.8\% of the GDP of Oman therefore venturing into a business of "Oxygen Bar" may be a better option being a new concept in Oman. This shows that there is a lot of potential in tourism in SME sector in Oman. Now let us understand the MSME sector in Oman context. Therefore we hypothesize that -

$\mathrm{H}_{2-}$ Oxygen Bar can be used to enhance entrepreneurial tourism in Oman

\section{RESEARCH METHODOLOGY:}

Quantitative and descriptive approaches were applied to collect information and data for exploring option of micro-entrepreneurial venture. The approach and technique used were as follows:

\section{Sampling design:}

Oman's one third population is youth, who can be the potential customers for the business leaders. This study included all business organizations involved in this type of business. It also included the consumers who are health conscious. Non- probability Judgmental sampling was used to get the relevant input to identify respondents for questionnaire administration. The non-probability convenience sampling technique was also used to identify respondents for this research. Approximately 200 potential respondents were administered the structured-undisguised questionnaire that was developed for the study. In the study 2 sample groups were taken; the first was is the Individual Respondent (local) that included around 150 respondents of questionnaire. The second sample was Individual Respondent (tourist): around 50 tourists from different countries were included in this group of sample. The whole sample group consisted of approximately 200

Valid questionnaires (response rate of $87.0 \%$ ) and 43 from business leaders (response rate of $82.0 \%$ ). Of the participants, $87.0 \%$ were men, and $13.0 \%$ were women. The average tenure in their jobs was 8.2 years. The most frequently indicated education level was a bachelor's degree (77.0\%), and most participants were business leaders $(23.0 \%)$. Convenience sampling method was selected to get an unbiased opinion about the items in the questionnaire. Existing research was built mainly on the primary data and we used questionnaires and unstructured interview to collect the data. These methods were adopted in this study to review the research objectives and to find responses of the research queries. Also this research was supported by some secondary data that were related to statistical figures of the respondents who were wishing to spend their time for recreational purpose and also to utilize all the secondary sources to get the scientific information about the oxygen bar. Different websites related to the topic was the source to obtain our secondary data. In addition we distributed questionnaire among a selected samples of people at random basis. The questionnaire helped us in gaining better knowledge on making this idea into a reality. The questionnaires were distributed by the distributors which enabled the researcher to take full advantage of asking the supplementary questions.

\section{Measures:}

Feasibility tests were conducted along with business leaders entrepreneurial venture into Oxygen Bar $(\alpha=$ $0.91)$. We conducted preliminary analysis by using marketing and financial feasibility questionnaires. This was conducted to screen project ideas before extensive time, effort, and money are invested. Two sets of activities are involved. The purpose was to find whether the planned venture would serve the purpose? The other question specifically focused to answer the question that are capital requirements for entry or continuing operations unavailable or unaffordable?

\section{Validity Analyses:}

To assess the discriminant validity of the measures in our study, we conducted a confirmatory factor analysis (CFA) for business leaders, marketing feasibility and financial feasibility. The results are presented in Table 1. The proposed two- factor model demonstrated a better fit to the data ( $\chi 2$ [200] $=297.625, \mathrm{p}<.001, \mathrm{CFI}=0.91, \mathrm{RMSEA}=0.07, \mathrm{IFI}=0.92, \mathrm{TLI}=0.92, \mathrm{RMR}=0.05)$. These results provide support for starting a new venture for business leaders. 


\section{FINDINGS:}

Ho predicts that Business leadership is significantly correlated with marketing feasibility analysis $(\mathrm{r}=.68$, $\mathrm{p}<.01)$, financial feasibility $(\mathrm{r}=.74, \mathrm{p}<.01)$. The result showed that proportion of variance was $19 \%$ and Chi square significant $(\chi 2=223.44, \mathrm{p}<.001)$. Model $2 \mathrm{H} 1$ predicts Business leadership is significantly correlated with marketing feasibility analysis $(\mathrm{r}=.70, \mathrm{p}<.01)$, financial feasibility $(\mathrm{r}=.77, \mathrm{p}<.01)$. The result showed that proportion of variance was $17 \%$ and Chi square significant $(\chi 2=203.44, p<.001)$. The findings are mentioned in Table- A1.

\section{DISCUSSION OF THE FINDINGS:}

Out of the total respondents to the questionnaire, $36 \%$ were male and $64 \%$ were female. Age categories: Most of the respondents i.e. $88 \%$ were of the age category 20-30. The respondents were asked whether they have heard about the oxygen bars before. From the selected samples $44 \%$ of them gave a positive response saying that they are aware of such relaxant which is there in most western countries. Times spend (in minutes) in one session. It was found that $28 \%$ of the respondent expressed satisfaction with 5 to 10 minutes of usage. $32 \%$ of the respondents expressed their satisfaction with 10 to 15 minutes of usage and $40 \%$ of the respondents expressed their satisfaction with 15 to 20 minutes of usage.

The data mentioned shows that $56 \%$ of the respondents exhibited satisfaction on the pricing and stated that the price was really reasonable and moderate. The findings shows that the price set by the researcher based on survey was quite feasible based on the target market.

\section{Analysis of data: tools \& techniques}

After gathering the primary data from the targeted group about their opinions and knowledge concerning the topic of this study, the responses on the interviewees and questionnaires were analyzed and presented in the results section. Translation of the answers of the respondents is very significant aspect of any research. Therefore, each question first revealed the findings chapter and then explains the benefits of the oxygen bar, presented in the discussion \& analysis part. In the data analysis portion, different techniques were used to recognize the conditions that attract those people to use oxygen bar. Secondary data were also used in this study. The combined correlation between the components of market feasibility and financial feasibility was found to be positively correlated (0.77) with the entrepreneurial options of opening an oxygen bar. Independently both the components of market feasibility and financial feasibility also showed positive correlation (0.71) for starting a new venture. The measure of internal consistency Chronbach alpha was found to be 0.812 which is considered good.

\section{Feasibility Evaluation:}

\section{Market feasibility:}

Market feasibility aims to identify (SWOT analysis) the strengths, weaknesses, opportunities and threats to the business from its stakeholders. It targets to figure out the resources and the tools needed to retain the strength, achieve the opportunities, overcome the weakness and face the threats successfully.

\section{Potential Market:}

The area of potential market after the survey was zeroed on Shatti Al-Qurum beach in Muscat. This area was chosen as many of the respondents favored this area because this area is an upscale residential locality and a place to many embassies apart from being the choice of many expatriates and home to many hotels. The research intended to serve the customer around this area including both tourist and locals from the center of setup project as this area attracted the tourists and the local population. Apart from this it was found that the potential market would find entry through making into contracts with some restaurants and hotels to reach out to more and wide range of customers. Taking the oxygen bar to the customer cost nothing, so it was assumed to be a beneficial step.

\section{Potential customer:}

For this research, the potential customers were in the age group of twenty to forty years who visit the area and the customer near to the location. The potential customers included both local and tourist around the 
area. As one part of the research findings focused on entering into contract with restaurant, hotels and malls, it was found that there is a high possibility that their customers could be the potential customers. In future also this idea of opening a new venture in "Oxygen Bar" was looked into for creative idea to draw people in and turn them into the potential customers. It was found that opening a new enterprise of oxygen bar in the selected area would attract the passers-by and they would stop for a taste for free flavored oxygen. We found that the potential customers would have a try at least once by visiting the booth for a minimum of 5 minutes. An oxygen bar is great strategy to start a new enterprise by getting people to stop and listen, while giving them the fun and new experience of trying flavored oxygen. The result found that since no other products can offer customers this type of relaxed and receptive audience, there is high possibility of having long list of potential customers at the oxygen bar once we are successfully able to promote its advantages.

\section{Existing competition:}

At present there is no oxygen bar at the Shatti Al-Qurum Beach. So it will be an advantage to start a new enterprise in this area by providing new services to the potential customers.

\section{Market strategy:}

Market strategy is being discussed with the 4Ps of marketing in detail.

\section{Products and pricing:}

The result found that the following services with the best quality possible within a reasonable stated price could attract customers providing them the highest level of satisfaction. To provide customer satisfaction was the main intention of this project as it would help to build up customer loyalty and goodwill. The result found feasibility of the following products and services along with their price and time taken by the customers of Oxygen bars. These are depicted in Table no. $1,2 \& 3$.

The above rates are kept as per the findings from the survey. This cost is feasible enough to sustain in the market. The result found that the profit margin is quite significant keeping operating cost into consideration. Therefore this may prove to be quite a profitable venture. As per oxygenbars.com the operating cost including aroma, oxygen and nose hose and cost to run the bar is $\$ 0.52$ per session and the customer is charged $\$ 11.00$ per session. This shows that this is quite a profitable business to venture in. Place- The choice of place is one of the main components of feasibility study. After the survey, the result found that providing all the services at the outlet in Shatti Al-Qurum would be feasible to start a venture in oxygen bar. The result found that since the venture would go into contract with local restaurants and hotels with the Oxygen Bar, the O2 Bars service would be available around the Shatti Al-Qurum Beach. PromotionThe result found that it would be feasible enough to use Social media such as Instagram, Facebook, Whatsapp and Mailing for promotional purposes as these social Medias are used almost on daily basis by the customers. Hence these social medias would be used to inform the customers about the promotion and provide sufficient information about oxygen bar products and services. The result found that distributing the leaflet and flyers in shopping malls would also be feasible and profitable for promoting the products. The extrapolated result found that after a year, the other promotional offers that can be used for the valued customers would be like; Buy-one-get-one-free and 10\% off. Ho predicts that Business leadership is significantly correlated with marketing feasibility analysis $(\mathrm{r}=.68, \mathrm{p}<.01)$. Model $2 \mathrm{H} 1$ predicts Business leadership is significantly correlated with marketing feasibility analysis $(\mathrm{r}=.70, \mathrm{p}<.01)$. The survey findings below show the SWOT analysis. $=19178-14564 / 19178=0.24$

Total contribution ratio is 0.24

Fixed cost $=39011$

Breakeven point in sales $=$ Total fixed cost/contribution ratio

\section{Swot Analysis:}

Table No. 4 depicts SWOT analysis of Oxygen Bar

\section{Estimation of Revenue:}

The findings of the feasibility analysis showed from Medium to high level of revenue generation and the profit accrued during the account year period. Cash basis accounting signifies the amount projected to be 
collected during a year of accounting period. This study found the expected profits/loss on opening a new venture in oxygen Bar. Since most important thing for predicting the revenue ought to follow the efficient strategies well, therefore the result suggested for the following strategies which are as follows:

1- Customer services (improve the customer services and develop a staff training program)

2- Increase the prices (checking the prices on services correctly and check the possibility to increase prices without reducing services)

3- Prioritizing the strategies: once the strategies to make the business more profitable was successful, it was suggested to give priority for other products in the order of their importance. It was suggested to pen down the goals to achieve them as it was a noble idea and also know the steps on how to implement those goals and objectives.

- The Age of group that were studied for this research was from (20-40years). The result found that oxygen bar would be more suitable for the customers of these ages as it would be more interesting for these age group of customers to try something new.

- The result found that the location of the oxygen bar would be at Shatti Al-Qurum in Muscat because this place is more popularly known by everyone and suitable for tourists. Break-even point (BEP) Contribution Ratio $(\mathrm{CR})=$ Total Revenue - Total variable cost $/$ Total Revenue $=39011 / 0.24=162,546$ The firm shall achieve BEP when sales will be of the amount USD162,546

\section{Market feasibility:}

According to the survey conducted by (Consumer Magazine 2002), it came to be known that the growing opportunity of starting such a business idea or a new venture in Oman. It was found that the data were really promising and were giving the hope of making profits with a sustainable market. It was found that as a growing economy and a widely tourist attracted destination in the GCC, starting an oxygen bar with other refreshments in Oman, would increase the business with new potential customers faster than expected. Both Omani and Non-Omani residents are fond of having a spot for relaxation after their busy day during the evenings or at least during the week ends. It was found that Shatti Al-Qurum. Beach would be a perfect spot for the business as it would give a boost to grow the business faster and would help in the expansion plans also. It was found that the main advantage of opening a new enterprise in oxygen bar is that at present there is no competition in the market and this idea is likely to give a new and exciting experience to the potential customers.

\section{Financial Feasibility:}

Ho predicts that Business leadership is significantly correlated with financial feasibility $(\mathrm{r}=.74, \mathrm{p}<.01)$. Model $2 \mathrm{H} 1$ predicts Business leadership is significantly correlated with, financial feasibility $(\mathrm{r}=.77, \mathrm{p}<$ .01 ). The figure represented the good fit and in the model. The study by (Consumer Magazine 2002) that the company would make an approximate profit of USD 20, 40.8 in the first year itself and it would increase in the following years if the market estimations remains the same. The depreciation value of the fixed assets is calculated at USD 160. It was assumed in the study that the salary of the staff and rent would remain static for the first three years at USD 155 and USD 100 respectively. The total of USD 700 would be spent for buying goods which is for sale. The fixed assets cost have high figures because of the high quality oxygen bar counters. The study by (Consumer Magazine 2002), found that the facts and figures of the revenue and the net profit are really promising and give high expectation in opening such a store or business firm in Oman.

\section{Problem and Opportunities:}

\section{Problems faced:}

1. The study assumed that it may be quite difficult to get the potential consumers accept this idea at the first instance

2. The study assumed that the person handling the oxygen bar counter should have good knowledge about the measures that to be taken.

3. The study cautioned that the new venture should be careful about the customers not making any medical claims, which can lead to legal issues and image of the company. 


\section{Opportunities available:}

1. There are not many competitors in this field at present, which would give the new starters an advantage.

2. Each session would last between 5 to 20 minutes. This would help give the new starters to attend more customers.

3. Oxygen bar has lots of health benefits (e.g.; relief from stress \& pollution, helps us to relax, ease headaches etc.) 4. The research found that starting a new venture of oxygen bar may prove to be a large market as one third of Oman's population is youth and they claim that oxygen bar may prove to be an alternative to shisha.

\section{Description of the proposed entrepreneurial venture:}

Business summary- The research found that selling oxygen for recreation would provide enhanced experience of taking in oxygen of different flavors, such as lavender or mint to the potential customers. The research also found that this entrepreneurial venture is likely to expand in the coming years at a later stage based on the consumers demand. The research also found that the market would expand by making a provision for booking the service of oxygen bar by specifying the flavors based on the wants of the customers.

\section{Location and Facilities:}

The research found that Shatti Al-Qurum in Muscat region would be the proposed feasible location to start a new venture by setting up an oxygen bar there. This proposed business is recommended as this location is situated at the heart of Muscat's beachfront tourist zone. It is perfectly suited for the business taking into consideration the target market, the environment required, the space required etc. The infrastructure of the area would also help in establishing the business. The research found some of the highlighted things about the place which are as follows:

1. Clean long stretch of sandy beach

2. Plenty of restaurants and hotels around it

3. Plenty of available parking area

4. Easily accessible the out-of-town visitors visit the beach when staying in Muscat, who would be the potential customers.

\section{Legal forms of the company:}

The research proposes to start the entrepreneurial venture in partnership with the local Omani citizen. Product and Services- The main products would be to sell oxygen for recreation purpose both "fixed" and "mobile". Apart from selling the main product, the research also proposes to provide fresh juice, coffee and few variety of fresh healthy fruit salad. The outcome of the study projects hundred percent comfort and relaxation to the customers.

\section{Long term aim of business:}

The long-term goal is to receive at least 95 percent positive customer feedback regarding the service that would be provided. It is also intended that this entrepreneurial venture would provide healthy products to the customers.

\section{Vision of the entrepreneurial venture:}

To provide best quality of oxygen bar services to the customers.

\section{LIMITATIONS OF THE STUDY:}

There were two challenges of this study. First was that the study may not be accurate as there were lack of numerous data and second the views of the respondents may have been biased.

\section{CONCLUSION:}

This paper performs market feasibility, financial feasibility and project the sales forecast by exploring the option of venturing into the business of "Oxygen Bar". The study was conducted for a location selected 
after the preliminary survey at Shatti Al-Qurum, Muscat in the Sultanate of Oman. The study shows that oxygen bar having health benefits may be an alternative to Shisha (a type of smoking) which is on rise in Oman and has harmful effects on the heath of smokers. According to (GYTS -Oman report 2010, pp. 21) around $38.5 \%$ of students aged 13-15 years who were shisha smokers wanted to quit shisha smoking but failed, therefore the study recommends using oxygen bar that may negate the effects of smoking shisha (though medical advice is required before this attempt). It can be concluded that new venture in "Oxygen Bar" in Oman is feasible and shall sustain smoothly in the market. Even though there would be difficulties in getting people's attention at the initial level, but eventually the business would perform great by generating high revenue in the long run. The main aim of the study was to know the market feasibility and financial feasibility for the business in the target market. Through the analysis of the questionnaire it was found that Oman market is a place that accepts and supports a new business idea which isn't much familiar to the local residents. The feasibility analysis conducted shows that the business would be able to gain good customer attraction and turn the potential customers to the actual customers of the organization and make good revenue and profit for the business. This would help the business to stay strong in the market and would help in the long run for sustaining the business.

\section{REFERENCES:}

Airheads Inc. (2016). Oxygen bar equipment sales. Retrieved November 17, 2016 from http://www.airheadsoxygenbars.com/oxygenbarsale s.html

Altman, N. (2007). The Oxygen Prescription: The Miracle of Oxidative Therapies. Rochester: Healing, 313-14

Breathe O2 (2011). Getting started. Retrieved October 14, 2011 from http://www.breatheo2.com/ gettingstarted.htm

Bren, L. (2002). Oxygen Bars: Is a Breath of Fresh Air Worth It? U.S. Food and Drug Administration (in FDA)

Central Intelligence Agency report (2016). The World Fact Book. Retrieved July 14, 2016 from https://www.cia.gov/library/publications/the-world-factbook/geos/mu.html

Construction World (2016). Kuwait's first oxygen bar called 'oasis'. ASAPP info global services Pvt ltd. Retrieved January 24, 2016 from http://www.constructionworld.ae/News.aspx?nId=nl hetuv0mww2idgp7ct + ga $==$ \&newstype $=$ kuwait-s-first-oxygen-bar-called-oasis-

Consumer magazine (2002). 36(6):9-11). Retrieved December 12, 2002 from https://www.ncbi.nlm.nih.gov/pubmed/12523293

Daller, J. (2017). Oxygen Bars - Is A Breath of Fresh Air Worth It? Retrieved November 22, 2017 from https://www.onhealth.com/content/l/oxygenbars-is-a-breath-of-fresh-air-worth-it

DePalma, A. (1997). Just when you thought air was free, New York Times (June 12, 1997): 7 in the oxygen prescription: The miracle of oxidative therapies by Nathaniel Altman, paperback-March 10, 2007.

Desertcart (2017). Retrieved October 4, 2017 from https://www.desertcart.ae/products/1911527-oxygenbar-in-a-can-boost-oxygen-natural-energy-22oz-natural-case-12-pack

Drahl, C. (2017). The Highs and Lows of Oxygen, Chemical and Engineering News 86.45 (2008):64

Globenewswire (2017). Global Consumer and Recreational Oxygen Equipment Markets 2017-2023. Retrieved November 12, 2017 from:

Gulf News General (2017). Fresh Air sale, Retrieved December 12, 2017 from http://gulfnews.com/news/uae/general/fresh-air-on-sale-1.403234

Gulf News Oman (2017). In crackdown, Oman issues new rules for shisha cafés. Retrieved, October 22, 2017 from http://gulfnews.com/news/gulf/oman/in-crackdown-oman-issues-new-rules-for-shishacafes-1.1834982

GYTS-Oman (2010). Global Youth Tobacco survey. World Health Organization, pp.12 https://globenewswire.com/news-release/2017/09/07/1113864/0/en/Global-Consumer-andRecreational-Oxygen-Equipment-Markets-2017-2023.html

Khan, F.R. \& Krishnamurthy, J (2016). Future proofing of tourism entrepreneurship in Oman: challenges and prospects, Journal of Work-Applied Management, Vol. 8 Issue: 1, pp.79-94, https://doi.org/10.1108/JWAM-06-2016-0008 
Koninklijke P (2017). The key benefits of Oxygen therapy. Retrieved October 20, 2017 from https://www.philips.co.in/healthcare/homecare/blog/benefits-of-oxygen-therapy

Medicinenet (2017). Oxygen Bars: Is a Breath of Fresh Air Worth It? Retrieved October 12, 2017 from http://www.medicinenet.com/script/main/art.asp? art iclekey $=21800$

MOM. (2005). Third symposium on employing national manpower, Shinas, Oman. Ministry of Manpower.

NSCI (2016). Share of the Tourism Sector in GDP, Retrieved November 15, 2016 from https://www.ncsi.gov.om/Pages/IndicatorDetails.aspx?ItemID $=5 f \% 2 f v v C z D b 8 l d x \% 2$ fna $9 \mathrm{~W} 2 \mathrm{gM}$ $w \% 3 d \% 3 d$

NSCI (2017). NSCI study plots economy drivers. Retrieved October 12, 2017 from https://www.pressreader.com/oman/times-of- oman/20170726/281573765762017

Oxygenbars.com (2017). Is breathing oxygen in an oxygen bar harmful? Retrieved November 22, 2017 from https://www.oxygenbars.com/knowledge-center/faq

Porter, H. (2003, September). A Culture of Enterprise. Business Today, 51-52

Reynolds, P. D., Bygrave, W. D., Autio, E., \& Arenius, P. (2004). GEM 2003 global report: Babson College.

RIYADA (2018). Retrieved November 15, 2018 from https://riyada.om/en-us/aboutus/Pages/ definesme.aspx

Shihadeh, A. (2003). Investigation of mainstream smoke aerosol of the argileh water pipe. Food and Chemical Toxicology. 2003, 41:143-152

SME Oman report (2016). Support. Partners in progress, Zubair SEC. Retrieved November 14, 2016 from http://www.zubairsec.org/downloads/SME_Oman_Report_2016_smaller.pdf

Susan, E (2017). Oxygen in a Can: Why Recreational Oxygen Is Gaining Traction. Retrieved November 02, 2017 from https://www.marketresearch.com/oxygen-in-a-can-why-recreational-oxygen-isgaining-traction

Times of Oman (2016). Oman health: Cigarettes and shisha fuelling lung cancer rise. Published on January, 31, 2016. Retrieved July 20, 2016 from http://timesofoman.com/article/76573/Oman/Health/ Lung-cancer-to-lead-to-cancer-diseases-in-coming-years-due-to-widespread-of-shishacigarettes-use- indisqussion-Odisqussion-Odisqussion-0

UNDP (2004). Unleashing entrepreneurship: Making business work for the poor: Report to the SecretaryGeneral of the United Nations by the Commission on the Private Sector \& Development. New York: UNDP. 1 March

Webmd (2017). The Rise of Oxygen Bars. Retrieved November 12, 2017 from https://www.webmd.com/balancelfeatures/rise-of-oxygen-bars\#1

WHO (2003). WHO study group on tobacco product regulation (TobReg). pp. 3. Retrieved July 12, 2003 from http://www.who.int/tobacco/global_interaction/tobre g/Waterpipe\%20recommendation _Final.pdf

World Bank Report (2010). Doing Business 2010. Washington, DC: The World Bank Group, IFC and Palgrave MacMillan

\section{TABLES}

Table No A1: Table 2 Means, standard deviations and correlations

\begin{tabular}{|l|c|c|c|c|c|c|c|c|c|c|}
\hline $\begin{array}{c}\text { Individual-level } \\
\text { variables }\end{array}$ & Mean & SD & $\mathbf{1}$ & $\mathbf{2}$ & $\mathbf{3}$ & $\mathbf{4}$ & $\mathbf{5}$ & $\mathbf{6}$ & $\mathbf{7}$ & $\mathbf{8}$ \\
\hline 1. Gender & 1.35 & 0.40 & & & & & & & & \\
\hline 2. Age & 31.42 & 4.62 & -0.12 & & & & & & & \\
\hline 3. Education & 4.00 & 0.71 & 0.24 & 0.02 & & & & & & \\
\hline
\end{tabular}




\begin{tabular}{|l|c|c|c|c|c|c|c|c|c|c|}
\hline $\begin{array}{l}\text { Individual-level } \\
\text { variables }\end{array}$ & Mean & SD & $\mathbf{1}$ & $\mathbf{2}$ & $\mathbf{3}$ & $\mathbf{4}$ & $\mathbf{5}$ & $\mathbf{6}$ & $\mathbf{7}$ & $\mathbf{8}$ \\
\hline 4. Tenure & 6.78 & 6.01 & -0.06 & $0.84 * *$ & -0.04 & & & & \\
\hline 5. Job type & 1.44 & 1.11 & 0.04 & 0.03 & -0.03 & 0.05 & & & & \\
\hline $\begin{array}{l}\text { 6. Business } \\
\text { leadership }\end{array}$ & 4.01 & 0.39 & -0.02 & -0.11 & 0.04 & -0.07 & 0.06 & & & \\
\hline $\begin{array}{l}\text { 7. Marketing } \\
\text { feasibility }\end{array}$ & 3.69 & 0.68 & -0.09 & -0.03 & -0.07 & -0.01 & -0.00 & -0.00 & & \\
\hline $\begin{array}{l}\text { 8. Financial } \\
\text { feasibuility }\end{array}$ & 4.06 & 0.71 & 0.10 & -0.08 & -0.01 & 0.03 & -0.10 & -0.02 & $0.62 * *$ & \\
\hline
\end{tabular}

Table No: 1

\begin{tabular}{|c|l|c|c|}
\hline \multicolumn{4}{|c|}{ Oxygen bar products } \\
\hline & \multicolumn{1}{|c|}{ Type of service } & Price (USD) & Time \\
\hline 1. & Inhaling oxygen & 8 & 10 \\
\hline 2. & Inhaling oxygen & 12 & 15 \\
\hline 3. & Inhaling oxygen & 15 & 20 \\
\hline
\end{tabular}

Table No: 2

\begin{tabular}{|c|l|c|c|}
\hline \multicolumn{3}{|c|}{ Tea and coffee types } \\
\hline \multicolumn{1}{|c|}{ Items } & Small (USD) & Medium (USD) \\
\hline 1. & Tea & 0.60 & 0.80 \\
\hline 2. & Zafran tea & 0.80 & 1.00 \\
\hline 3. & Milk Zafran & 1.300 & 1.800 \\
\hline 4. & Green tea & 0.60 & 0.80 \\
\hline 5. & Black tea & 0.60 & 0.80 \\
\hline 6. & Green tea mint & 0.60 & 0.80 \\
\hline 7. & Nescafé & 0.300 & 2.600 \\
\hline 8. & Cappuccino & 2.600 & 1.200 \\
\hline 9. & Americano & 3.100 & 3.600 \\
\hline 10. & Coffee Latte & 3.100 & 3.600 \\
\hline 11. & Caf Mocha & 3.600 & 4.100 \\
\hline
\end{tabular}


Table No: 3

\begin{tabular}{|c|c|c|c|}
\hline \multicolumn{4}{|c|}{ Cocktail \& Juices } \\
\hline & Items & Small & Medium \\
\hline 1. & Mango & 2.600 & 3.100 \\
\hline 2. & Orange & 2.600 & 3.100 \\
\hline 3. & Lemon & 2.600 & 3.100 \\
\hline 4. & Apple & 2.600 & 3.100 \\
\hline 5. & Carrot & 2.600 & 3.100 \\
\hline 6. & Guava & 2.600 & 3.100 \\
\hline 7. & Musk Melon & 2.600 & 3.100 \\
\hline 8. & Banana milk shake & 3.100 & 3.600 \\
\hline 9. & Apple milk shake & 3.100 & 3.600 \\
\hline 10. & Fruit cocktail & 3.100 & 3.600 \\
\hline 11. & Fruit salad & 3.600 & 4.100 \\
\hline
\end{tabular}

Table No: 4

\section{Strengths}

No competition in the market Weakness

Environment friendly Low/no harmful Concept is new to the business world chemicals

\section{Opportunities}

Likely to become a new image and symbol of business in that area.

Much potential for future development

It may not acceptable by all customers

\section{Threats}

Conceptual success may attract more competitors Unawareness about the oxygen Bar advantages in the locality 